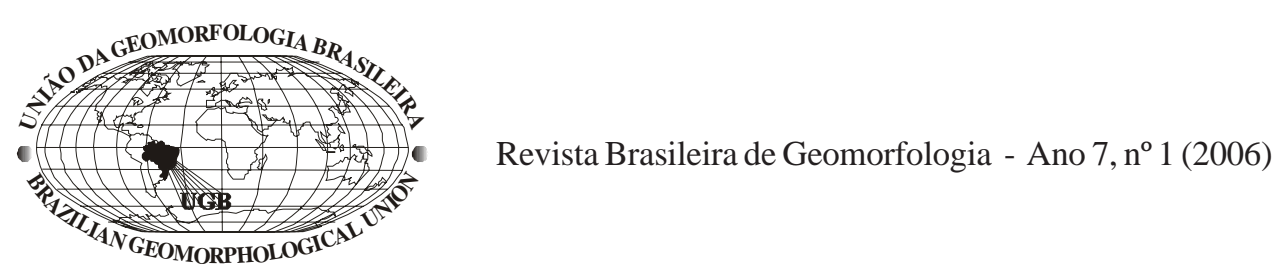

\title{
MECANISMOS DE INICIAÇÃO DE FLUXOS DETRÍTICOS NO MACIÇO DA TIJUCA, RIO DE JANEIRO(RJ): O CASO DA ENCOSTA DO SOBERBO
}

\author{
André de Souza Avelar \\ Professor Adjunto, Depto. de Geografia/IGEO-UFRJ \\ andreavelar@acd.ufrj.br \\ Willy Alvarenga Lacerda \\ Professor Titular, Geotecnia/COPPE-UFRJ; Pesquisador 1-A/CNPq \\ willy@coppe.ufrj.br \\ Ana Luiza Coelho Netto \\ Professora Titular, Depto. de Geografia/IGEO-UFRJ; Pesquisadora 1-B/CNPq \\ ananetto@acd.ufrj.br
}

\begin{abstract}
Resumo
O trabalho enfoca as causas da iniciação do fluxo detrítico da encosta do Soberbo, que, segundo a literatura, deveu-se ao impacto da queda de um bloco de rocha no solo saturado. Objetivando confirmar esta possibilidade de iniciação foram levantadas as condições geomorfológicas e geotécnicas da área, antes e após o movimento de massa inicial e foram realizados ensaios triaxiais convencionais (estático) e de choque não-drenado (dinâmico) no colúvio e no saprolito existentes na encosta. As características geomorfológicas foram extraídas da literatura e a partir de aerofotos de 1954 e 1967, indicando a ocorrência de blocos de rocha propícios à queda e o local de iniciação da ruptura. Os ensaios de choque provaram que as rupturas no colúvio ocorrem com carregamentos bem menores que àqueles necessários para a ruptura sob carga estática. Concluiu-se que a queda do bloco rochoso produziu a liquefação do colúvio que iniciou o fluxo detrítico do Soberbo.
\end{abstract}

Palavras-chaves: fluxos detríticos, movimentos de massa, ruptura por impacto, liquefação de solos.

\begin{abstract}
This study considers the causes of the Soberbo debris flow initiation in Rio de Janeiro, Brazil. According to the literature the initial failure occurred due to the impact of a rock block against the saturated soil. To confirm that hypothesis, were ivestigated the geomorphological and geotechnical conditions on Soberbo slope, before and after the initial mass movement. Undrained shock tests in a colluvium and saprolite occurring in the Soberbo slope were also carried out. The geomorphological features were reconstructed with data found in the literature and from aerial photos took in 1954 and 1967, which showed the occurrence of rock blocks and indicated the initial point of slope failure. The shock tests results show that the failure of the Soberbo's colluvium happened with lower loads comparing to the static failure loads applied in triaxial tests. It was concluded that initiation of the Soberbo debris flow was caused by the impact of this rock block against the colluvium.
\end{abstract}

Keywords : debris flows, landslides, failure by impact, soil liquefaction

\section{Introdução}

Os movimentos de massa são os principais processos geomorfológicos modificadores do relevo nos domínios montanhosos. Dentre eles, os fluxos detríticos são os que apresentam geralmente maior magnitude e intensidade de modificação do relevo, podendo alcançar dimensões catastróficas. Estes fluxos têm início após a liquefação do solo na encosta devido à elevação súbita da poro-pressão (INNES, 1983; JOHNSON \& RODINE, 1984; SASSA, 1985 e 1989; PIERSON \& COSTA, 1987; PEDROSA et al., 1988; TAKAHASHI, 2000; IVERSON et al., 2000; HUNGR, 2002). 
A liquefação é transformação do estado sólido para o líquido, como conseqüência da geração de poro-pressão responsável pela redução da tensão efetiva (Kubota \& Takeda, 1998). Após a iniciação ocorre a propagação (run out, Hungr, 1995), que é o deslocamento da massa liquefeita pelas encostas ou fundos de vale, finalizando-se na deposição. Durante a propagação há a incorporação dos materiais detríticos em sua trajetória: matacões, blocos de rochas, areia, silte, argila e restos vegetais (as vezes, árvores inteiras). Isto se dá com velocidade e densidade elevadas, gerando energia cinética altamente destrutiva e catastrófica.

No Brasil, alguns autores os têm denominado como "corridas de massa ou de detritos", porém, como o termo fluxo se refere a um processo físico, e corrida não, tem-se preferido a denominação aqui utilizada. Além disso, o termo fluxos detríticos (ou fluxo de detritos) mostra-se mais adequado à tradução de debris flows, que é o termo em inglês.

Na literatura geomorfológica e geotécnica três mecanismos são considerados na iniciação destes fluxos: (1) através da erosão fluvial em canais de drenagem; (2) devido ao aumento de poro-pressão pela infiltração e (3) devido ao aumento de poro-pressão causado por carregamento muito rápido (Sassa, 1985, 1989; Eckersley, 1990; Bovis \& Dagg, 1992; Takahashi, 2000; Iverson et al., 2000). O primeiro atua sob vazões críticas instabilizadoras, causadas pelo efeito cisalhante da água corrente no depósito abaixo do canal, advindas de chuvas intensas, derretimento de neve ou ruptura de barragens. O segundo se dá pelo súbito acréscimo de poro-pressão devido à recarga da zona saturada durante chuvas muito intensas. O terceiro se dá pelo impacto causado a partir de movimentos de massa ocorrido a montante sobre depósitos em fundos de vale, tal como citado em Evans \& Hungr (1993), Sassa (1985), Hiura et al. (1985), Bovis \& Dagg (1992), Barros et al. (1992), Lacerda \& Schilling (1993) e Vieira et al. (1997).

Sassa (1985) propôs um modelo similar no Japão, onde, após a ruptura na alta encosta a massa rompida choca-se sobre um depósito arenoso e fofo na base, causando liquefação e produção do fluxo detrítico (figura 1), também descrito por Reneau \& Dietrich (1987).

Innes (1983) coloca que o início do fluxo na base de escarpas é possível após carregamento não-drenado devido à queda de rocha da escarpa. Bovis \& Dagg (1992) mencionam fluxos de detritos no Canadá gerados por ruptura de materiais a montante sobre depósitos de fundos de vale, gerando um modelo de impacto (figura 2).

O comportamento dos solos sob choque foi estudado por Sassa (1985) em areias fofas e compactas, que seguem os caminhos de tensão ${ }^{1}$ mostradas na figura 3 . As curvas A e B são para o cisalhamento drenado de areia fofa e compacta, enquanto C e D representam tais estados sob cisalhamento não-drenado.

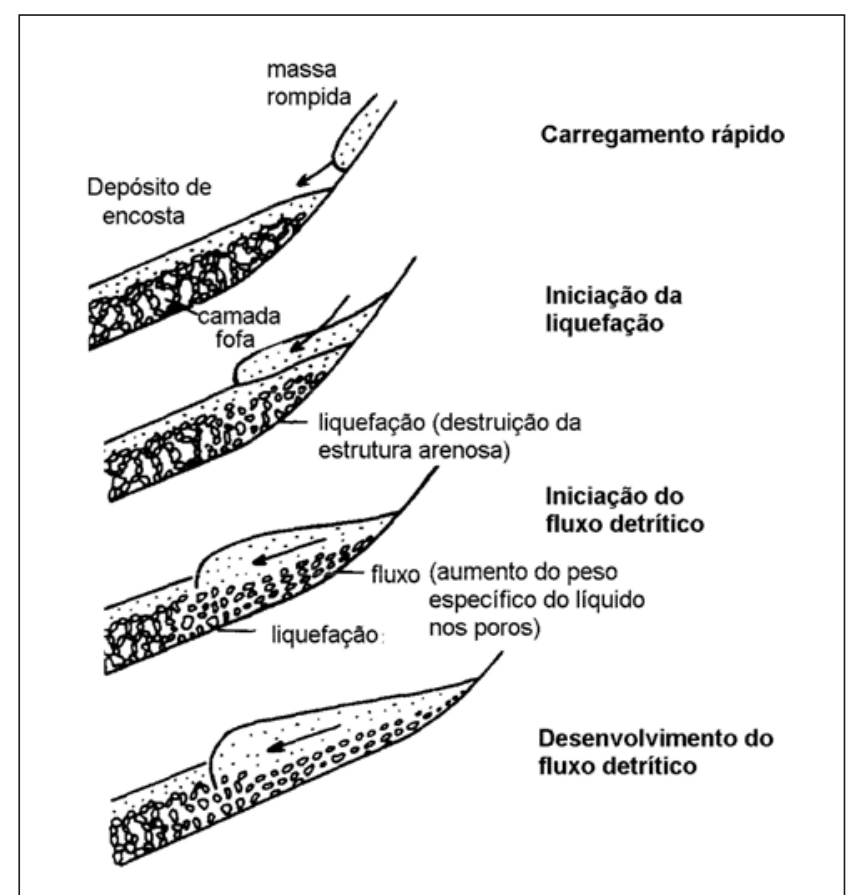

Figura 1 - Mecanismo de iniciação de um fluxo detrítico produzido por impacto (Sassa, 1985).

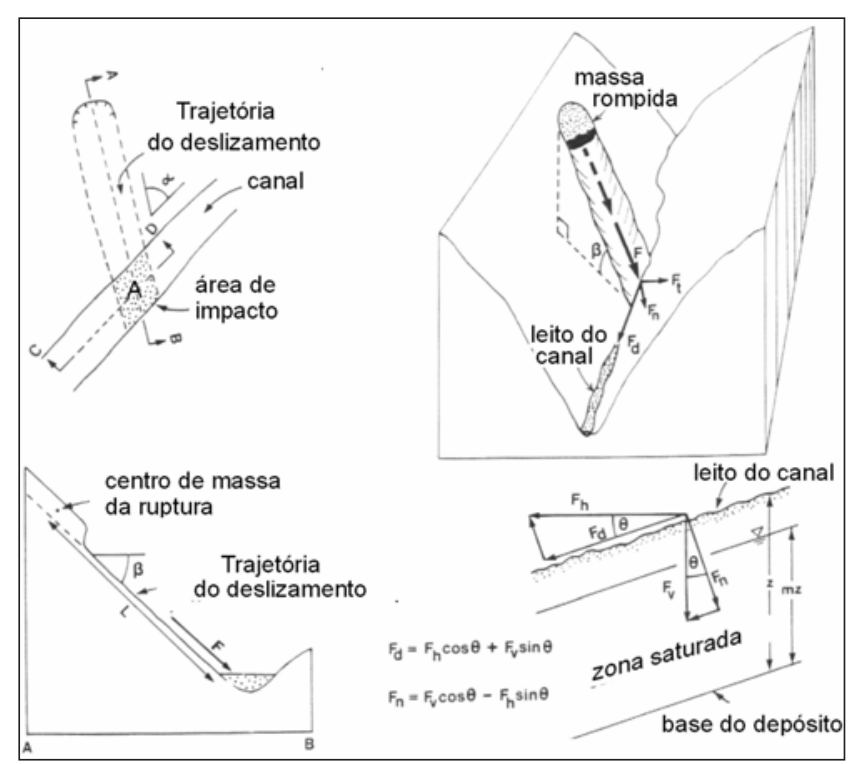

Figura 2 - Modelo de iniciação de fluxos detríticos por impacto (Bovis \& Dagg, 1992).

\footnotetext{
${ }^{1}$ Os caminhos de tensão provém de ensaios triaxiais de resistência ao cisalhamento realizados na mecânica dos solos e são apresentados em gráficos de tensão normal (ou $\mathrm{P}$ ) e tensão cisalhante (ou Q), designados pela relação: $\mathrm{P}=\left(\sigma_{1}+\sigma_{3}\right) / 2$ e $\mathrm{Q}=\left(\sigma_{1}-\sigma_{3}\right) / 2$. Quando os ensaios são não-drenados e se mede a poro-pressão (u), calcula-se os valores das tensões efetivas ( $\left.\sigma^{\prime}\right)$, isto é; $\sigma^{\prime}=\sigma-\mathrm{u}$, e as relações são designadas como; $\mathrm{P}=\left(\sigma_{1}^{\prime}+\sigma_{3}^{\prime}\right) / 2$ e $\mathrm{Q}^{\prime}=\mathrm{Q}=\left(\sigma_{1}^{\prime}+\sigma_{3}^{\prime}\right) / 2$.
} 
Ensaios de cisalhamento triaxial não-drenado de areias fofas submetidas a choque (figura 4) apontam súbita ruptura da amostra (liquefação), mostrando comportamentos similares aos das condições C e D da figura 3.

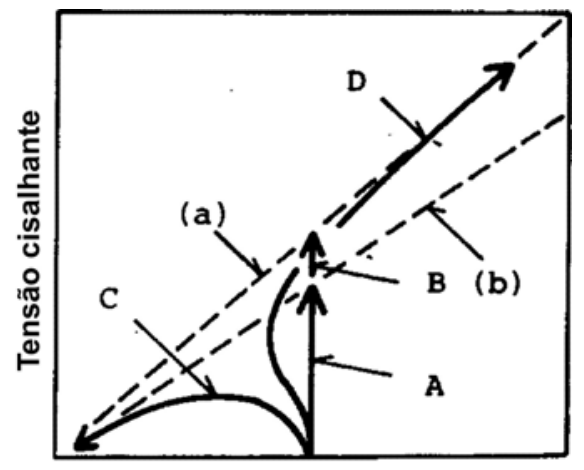

Tensão normal

Figura 3 - Caminho de tensões para cisalhamento de areias. A reta tracejada (a) é a envoltória de ruptura para areias compactas e a reta (b) para areias fofas. As trajetórias A e B representam areias fofas e compactas em ensaios drenados, enquanto que as trajetórias $\mathrm{C}$ e D representam tais estados em ensaios não-drenados (Sassa, 1985).

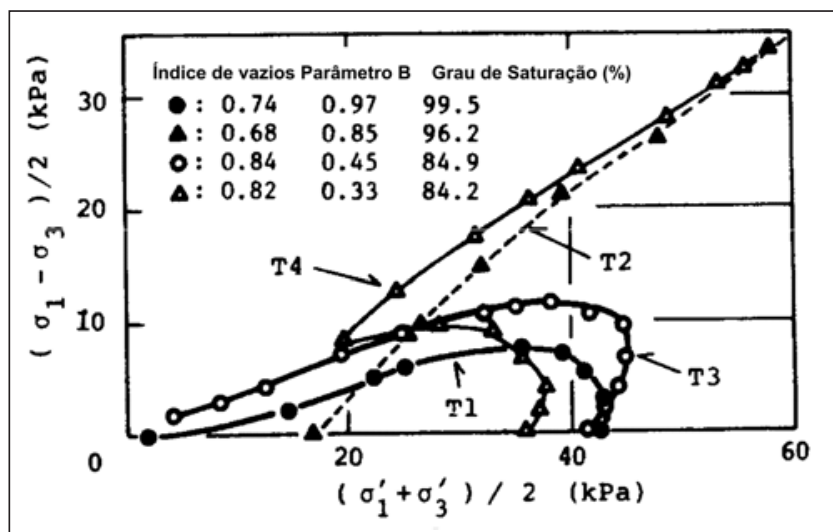

Figura 4 - Gráfico de ensaios de choque em solos de encosta (Sassa, 1985). T1 indica liquefação do solo fofo saturado; T3 traz o comportamento do solo não-saturado $(84,9 \%)$, indicando também a ocorrência de liquefação; T2 e T4 representam rupturas por cisalhamento convencional.

O fluxo detrítico do Soberbo tem histórico e características geológicas, geomorfológicas e geotécnicas detalhados na literatura, sendo sua iniciação pouco clara: se devido ao choque do bloco de rocha na massa de solo ou apenas por saturação advinda de infiltração e súbito aumento de poro-pressão.

Este trabalho objetivou definir o comportamento dos solos do Soberbo frente ao impacto e verificar se os resultados são compatíveis às condições de campo do evento. Para tanto buscou-se conhecer as condições geomorfológicas antes e após o evento e a possibilidade de ruptura por impacto através de ensaios de choque. Pretendeuse, desta forma, subsidiar a modelagem física dos movimentos de massa do tipo fluxo detrítico com foco sobre a iniciação. Vale ressaltar que este mecanismo é comum não apenas no maciço da Tijuca, mas também em outras regiões montanhosas sob distintas condições ambientais.

\section{O fluxo detrítico do Soberbo e características da área no contexto do Maciço da Tijuca}

A encosta do Soberbo fica na bacia do Córrego Santo Antônio, afluente do rio Cachoeira, na vertente sudoeste do Maciço da Tijuca, RJ (figura 5). Barros et al. (1992) relata que a primeira ação do movimento de massa do Soberbo deu-se em 14/JAN/1966 como uma avalanche de grandes proporções que percorreu $800 \mathrm{~m}$, gerada após grandes chuvas, quando um bloco de rocha se deslocou por gravidade da parte alta da encosta, próximo a cota 430 m, a montante da Estrada do Soberbo.

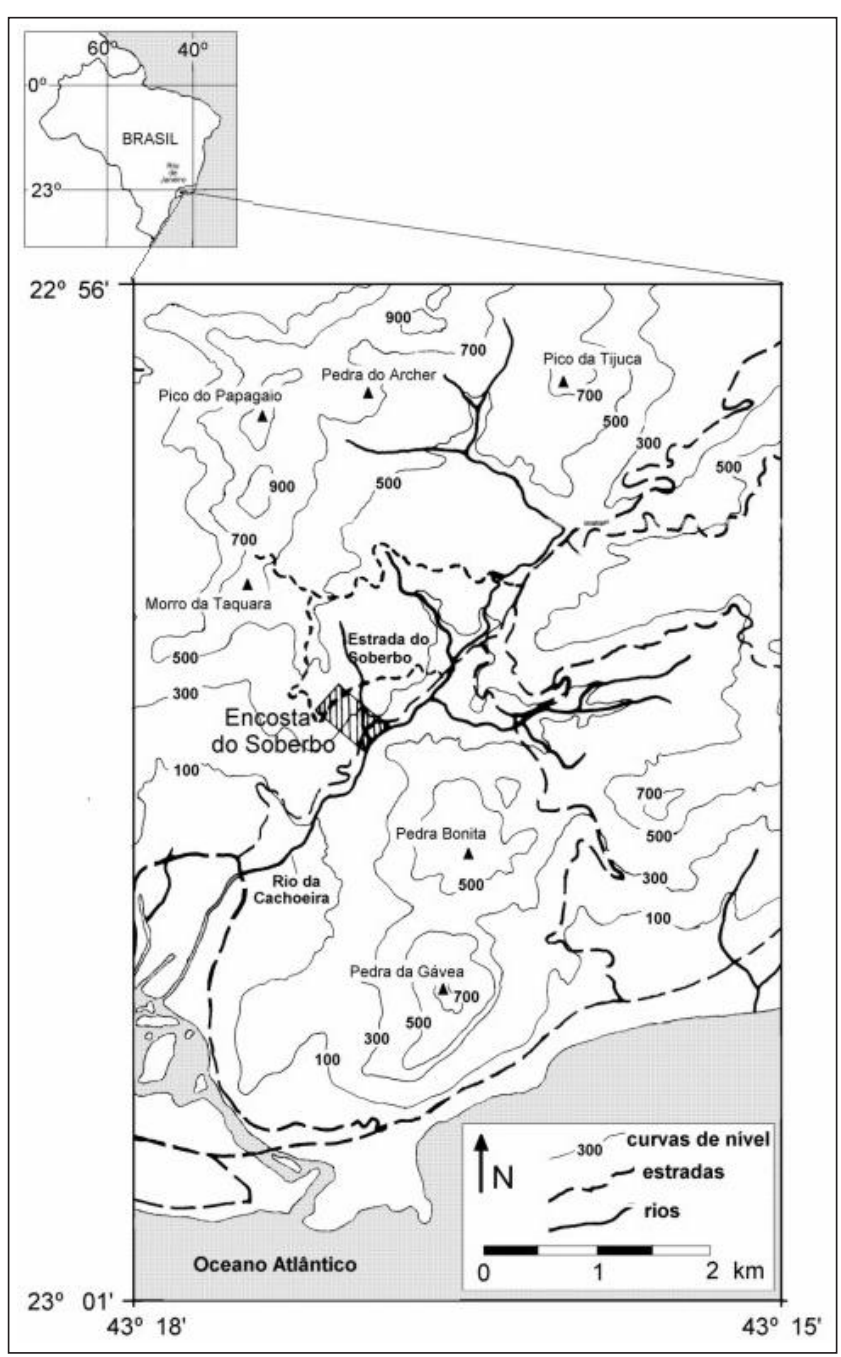

Figura 5 - Localização da encosta do Soberbo 
Este início se deu na zona A (figura 6), com ruptura parcial da estrada. Após $48 \mathrm{~h}$ houve a primeira avalanche e dois novos movimentos distintos, nas zonas B e C: um movimento translacional e uma faixa abatida com $4 \mathrm{~m}$ de largura, respectivamente, juntando-se em "Y", separados por larga área a montante, onde uma casa nada sofreu. Fonseca (1969) ressalta, por sua vez, que o início do movimento ocorreu após 4 dias de chuvas, com uma grande avalanche que detonou com a queda por gravidade de um grande bloco de rocha a partir da cota $430 \mathrm{~m}$ na zona A.
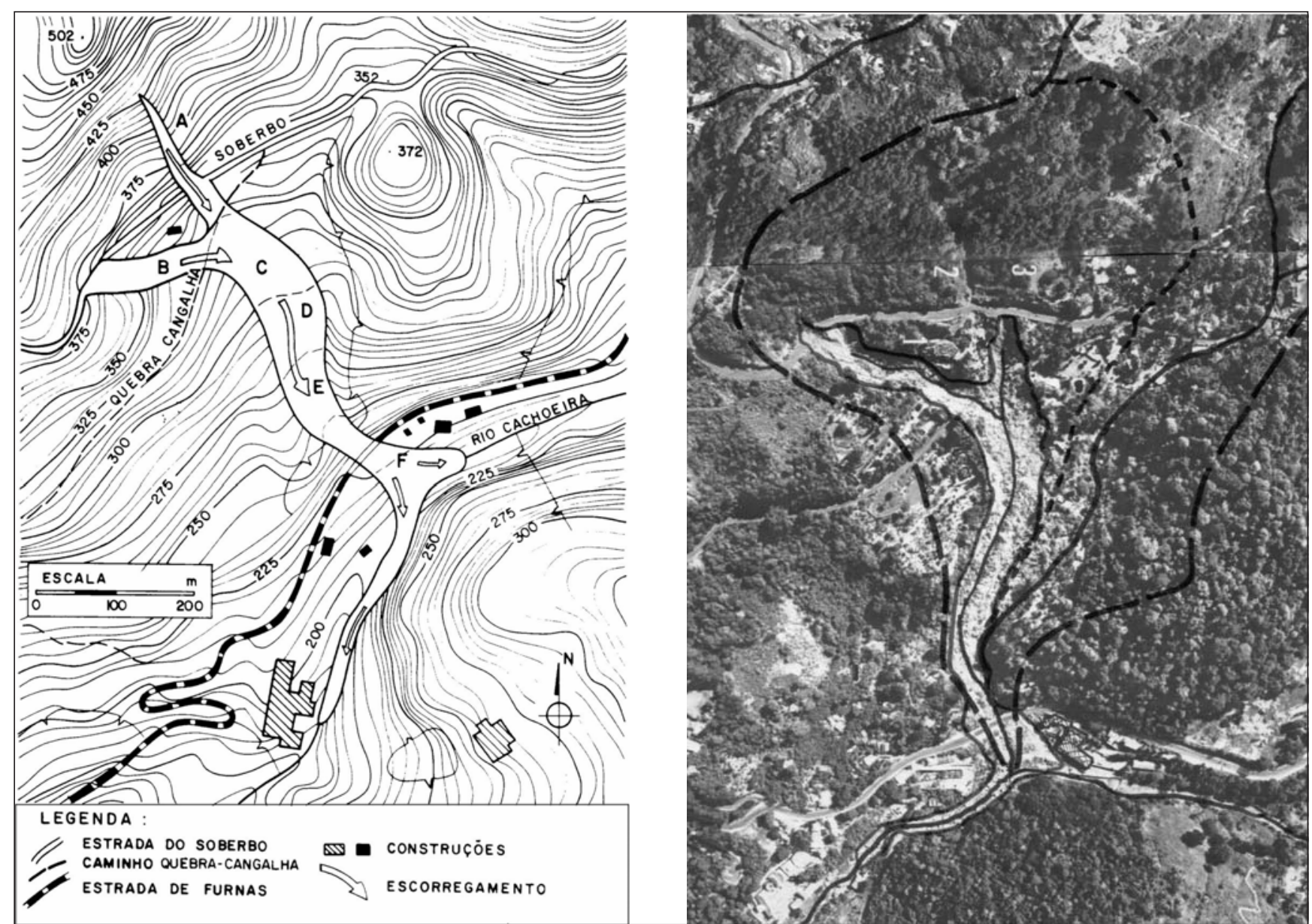

Figura 6 - Topografia detalhada (PEDROSA et al., 1988) e interpretação da foto aérea de 1967 do fluxo detrítico na encosta do Soberbo (AVELAR, 1996).

A geologia da área (AMARAL et al., 1992) apresenta uma intrusão de diorito envolta por granito equigranular leucocrático, encaixadas em gnaisse e cortadas por diques de diabásio e bolsões pegmatíticos pontuais, com fraturas de alívio e fraturas sub-verticais orientadas ao longo da encosta.

As fraturas de alívio e sub-verticais são feições estruturais comuns no substrato rochoso de todo o Maciço da Tijuca, com orientação dominante para NW-SE e NE-SW. A interconexão destas estruturas favorece a formação de lascas de rochas e blocos in situ. Os picos arredondados e as escarpas rochosas sob forte declividade $\left(>50^{\circ}\right)$ são feições morfológicas conspícuas que operam em superfície, ou através do sistema de fraturas e juntas, como zonas de recarga de água em profundidade nos solos (COELHO NETTO, 1985).
Os colúvios ricos em blocos são comuns neste ambiente montanhoso, especialmente nos degraus estruturais associados com rupturas de declives e nos fundos de vales (CRUZ et al., 1998). Estão no rastro dos movimentos de massa rápidos (translacional ou fluxos detríticos) ocorridos em tempo geológico recente, assim como ocorre nos dias atuais.

A encosta do Soberbo situa-se sobre o diorito, com presença de solo saprolítico, colúvio e alguns afloramentos. Trabalhos anteriores definiram a estratigrafia e parâmetros geotécnicos (PEDROSA et al., 1988; SILVEIRA \& LACERDA, 1992; SANTOS JR., 1996; AVELAR \& LACERDA, 1997). O saprolito é areno-siltoso, com índice de vazios em torno de 1,0; enquanto o colúvio é heterogêneo, com matriz argiloarenosa que envolve pedregulhos a blocos, com espessura 
de 2 a $10 \mathrm{~m}$. A matriz possui elevado índice de vazios, variando de 1,8 a 2,4 .

A porção média-superior do Maciço da Tijuca é a área mais úmida da cidade; a precipitação média anual é de $2300 \mathrm{~mm}$ variando entre 1.300 e 3.000 mm (COELHO NETTO, 1985), com chuvas intensas ocorrendo em Janeiro e Fevereiro. Em anos regulares a chuva média mensal destes meses variaem torno de $250 \mathrm{~mm}$, mas sob condições extremas podem ultrapassar 800 mm, como ocorreu em Fevereiro de 1988 (900 $\mathrm{mm})$ e Fevereiro de 1996 ( $800 \mathrm{~mm})$. Nestes dois anos ocorreram inúmeros e extensos deslizamentos no Maciço da Tijuca, predominando os movimentos translacionais e os fluxos detríticos (COELHO NETTO,1996). Nos verões antecedentes de 1966 e 1967, houve vários movimentos de massa com chuvas intensas e longa duração, superando os eventos registrados até aqueles anos (BARATA, 1969). A precipitação atingiu 617,6 mm em JAN/1966, sendo 472,0 mm em 72 h consecutivas, nos dias 11, 12 e 13 (MEIS \& SILVA, 1968).

\section{Metodologia}

Diversas categorias foram mapeadas em dois períodos na encosta do Soberbo: vegetação e uso do solo, topografia, feições erosivas, disposição de blocos de rochas e canais de drenagem. Para comparação, utilizou-se fotos aéreas anteriores ao deslizamento do Soberbo (fotos de 1954, escala 1:3.500) e posteriores, através de fotos de agosto de 1967 (escala 1:5.000).

Amostras indeformadas de colúvio e saprolito foram coletadas para realização de ensaios triaxiais não-drenados, submetido a tensões confinantes efetivas de 25, 200 e 600 kPa (condições de tensão de campo) para obtenção dos parâmetros de ruptura e dos caminhos de tensões percorridos até a ruptura. Além disso, forneceram valores para a modelagem dos ensaios de ruptura por impacto (ensaios de choque). Por fim foram feitos os ensaios de choque, executados em célula triaxial, com aplicação instantânea de carga (choque) e medição da tensão aplicada, deformação, poro-pressão e energia de choque. Os ensaios de choque foram executados com tensão confinante efetiva inicial de 25 $\mathrm{kPa}$, para simular a tensão de confinamento de campo próximo a superfície do terreno. Escolheu-se o saprolito e o colúvio que ocorrem na zona A do movimento de massa do Soberbo, onde houve a queda do bloco de rocha responsável pela iniciação do fluxo detrítico. As tensões desvio durante a ruptura por cisalhamento, sob tensão confinante de $25 \mathrm{kPa}$, foram usadas na definição da carga de ruptura estática, que balizou os ensaios de choque não-drenado.

Nestes ensaios deixa-se uma massa conhecida cair de uma certa altura em queda livre, sobre uma plataforma circular de alumínio fixada ao pistão da célula traxial (figura 7). Com o equipamento disponível no Laboratório de Geotecnia da
COPPE/UFRJ registrou-se automaticamente o deslocamento axial, a poro-pressão na base, a força aplicada e a pressão confinante (AVELAR, 1996, 2003). As alturas de queda foram 10,15 ou $20 \mathrm{~cm}$. As massas usadas no saprolito foram 2,050; 4,100 e 8,550 kg correspondentes a 6, 12 e $25 \%$ do pico de tensão desvio (estática) necessária para ruptura. Nos colúvios foram massas de 0,620; 1,300;2,580 kg e 5,160 kg sendo 6, 12, 25 e 50\% da tensão desvio necessária para ruptura estática.

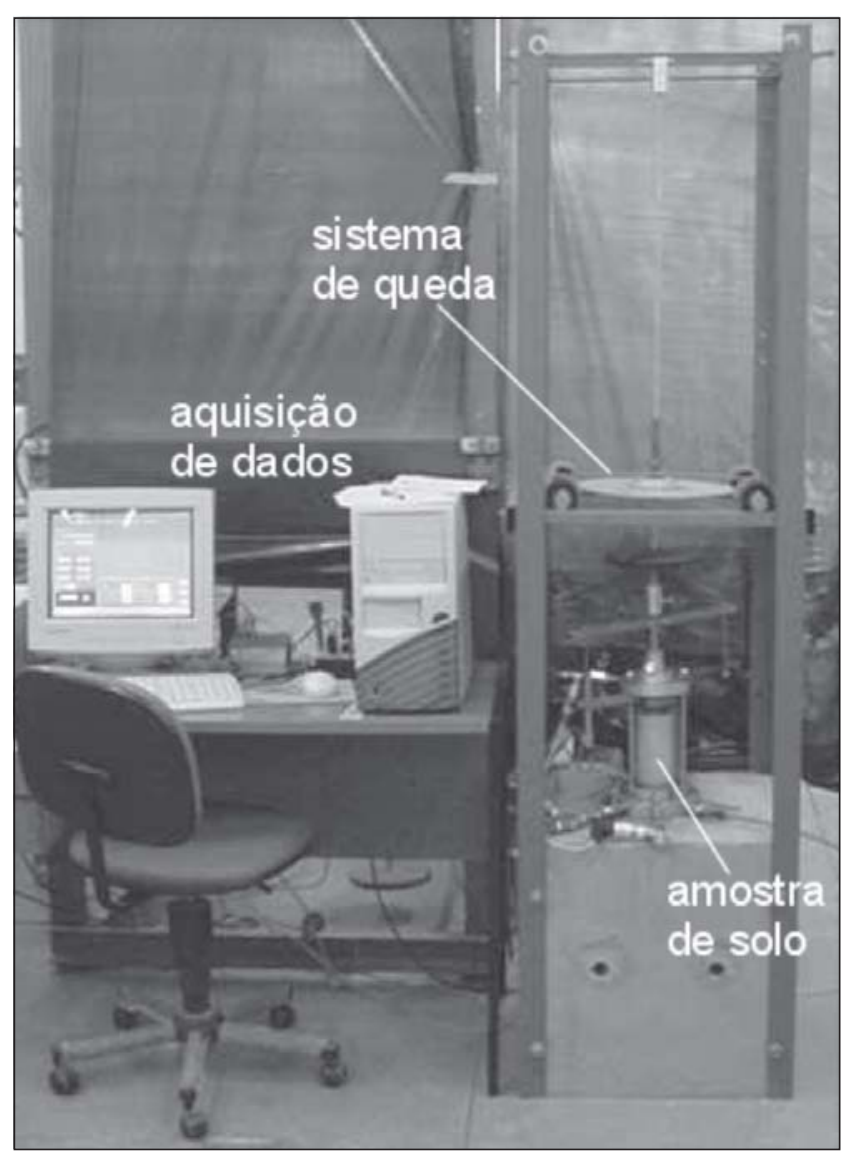

Figura 7 - Equipamento para ensaios triaxiais de choque (AVELAR, 2003).

\section{Uso do solo antecedente e posterior ao fluxo detrítico do Soberbo}

As fotos de 1954 (1:3.500) mostram atividades agrícolas e mineração (granito ornamental), junto com vias de acesso e elevado número de residências. Percebe-se a presença de vários blocos de rocha, algumas cicatrizes de erosão e ocorrência de gramíneas e floresta na parte superior da encosta. Vale destacar que a mineração progrediu ao longo de dois fundos vales íngremes, os quais convergem para o eixo do vale onde ocorreu o fluxo do Soberbo. Na base a mineração observou-se a ocorrência de três blocos de rochas com cerca de 3m de diâmetro cada um, os quais, pela posição 
e informações locais, podem ter sido os responsáveis pela detonação do deslizamento. Com efeito, os vales menores podem ter drenado fluxos d'água superficiais com intenso potencial erosivo ao redor dos blocos levando-os ao deslocamento e posterior queda.

A marcação do contorno do deslizamento pelas fotos de 1967 mostrou que este ocorreu inteiramente em fundo de vale, destruindo quatro casas que estavam na rota do deslizamento. Vale ressaltar que neste ano a atividade agrícola já estava retraída, assim como a mineração também já havia se deslocado para outras áreas vizinhas.

\section{Comportamento não-drenado dos solos do Soberbo frente à resistência ao cisalhamento $\mathrm{e}$ ao choque}

Os parâmetros de ruptura dos solos e os gráficos dos ensaios não-drenados estão na tabela 1 e figura 8. No saprolito a envoltória de ruptura do gráfico $\mathrm{P}^{\prime}-\mathrm{Q}^{2}$ apresenta $\mathrm{a}^{\prime}=24 \mathrm{o}$ e a $=20 \mathrm{kPa}$, caracterizando ângulo de atrito de 26,40 e coesão de 22,3 kPa; no gráfico central observa-se tensões desvio de ruptura de 160, 150 e 350 kPa e deformações axiais de ruptura de 5 a $7 \%$; enquanto as poro-pressões durante 0 cisalhamento foram distintas, com tensão confinada de 25 $\mathrm{kPa}$ houve pequeno acréscimo (cerca de $35 \mathrm{kPa}$ ), indicando que saprolito apresenta alguma dilatância, ao contrário do que foi observado nos confinamentos de 200 e $600 \mathrm{kPa}$.

Tabela 1 - Parâmetros de ruptura dos solos do Soberbo: $\sigma^{\prime}{ }_{c}$ tensão confinante efetiva, $\sigma_{\mathrm{dr}}$ tensão desvio de ruptura, $\varepsilon_{\mathrm{a}}$ deformação axial de ruptura, $\phi$ ' ângulo de atrito efetivo e c’coesão verdadeira.

\begin{tabular}{|cccccc|}
\hline Solo & $\begin{array}{c}\sigma^{\prime}{ }_{\mathbf{c}} \\
(\mathbf{k P a})\end{array}$ & $\begin{array}{c}\sigma_{\mathrm{dr}} \\
(\mathbf{k P a})\end{array}$ & $\begin{array}{c}\varepsilon_{\mathrm{a}} \\
\mathbf{( \% )}\end{array}$ & $\begin{array}{c}\phi^{\prime} \\
(\mathbf{g r a u s})\end{array}$ & $\begin{array}{c}\mathbf{c}^{\prime} \\
(\mathbf{k P a})\end{array}$ \\
\hline \multirow{3}{*}{ saprolito } & 25 & 160 & 6,0 & & \\
& 200 & 150 & 5,0 & $26,4^{\circ}$ & 22,3 \\
& 600 & 350 & 7,0 & & \\
\hline \multirow{3}{*}{ colúvio } & 25 & 50 & 2,0 & & \\
& 200 & 100 & 3,0 & $29,9^{\circ}$ & 9,2 \\
& 600 & 350 & 4,0 & & \\
\hline
\end{tabular}

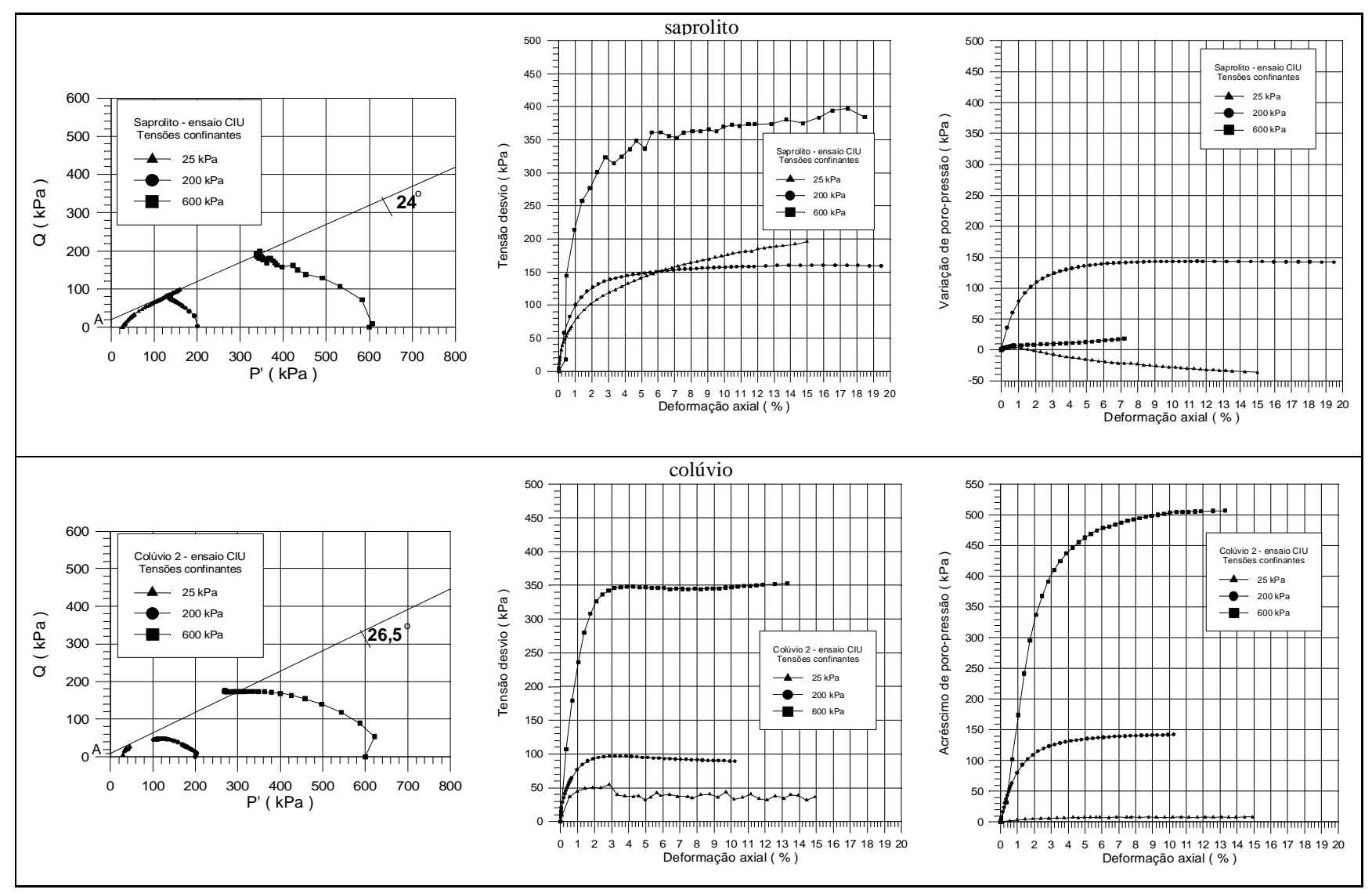

Figura 8 - Comportamento do saprolito e colúvio em ensaios triaxiais não-drenados (AVELAR, 1996).

\footnotetext{
${ }^{2} \mathrm{O}$ cálculo de $\phi^{\prime}$ e c' a partir dos gráficos P'-Q se faz através das equações: $\operatorname{tg} \alpha^{\prime}=\operatorname{sem} \phi^{\prime}$ e $c^{\prime}=a / \cos \phi^{\prime}$.
} 
A envoltória de ruptura do colúvio no diagrama P'-Q mostra $\alpha^{\prime}=26,5^{\circ}$ e A $=8 \mathrm{kPa}$, fornece $\phi^{\prime}=29,9^{\circ}$ e c' $=9,2 \mathrm{kPa}$. As tensões desvio de ruptura atingiram 50, 100 e $350 \mathrm{kPa}$ com deformações axiais de 2 a $4 \%$; enquanto as poropressões seguem o comportamento das tensões desvio com máximos de 10, 140 e $510 \mathrm{kPa}$, indicando que o colúvio é compressível durante o cisalhamento.

\subsection{Liquefação em ensaios de choque}

O comportamento do saprolito nos ensaios triaxiais não-drenados de choque (figuras 9 e 10) mostra que a força gerada pela queda da massa de 4,100 $\mathrm{kg}$ atingiu o pico de $0,2782 \mathrm{kN}$, ou seja, 28,36 kgf. Esta carga é 6,9 vezes maior que a carga estática de $0,0402 \mathrm{kN}$ dada pelo peso de 4,100 kgf em repouso. Este valor de pico é muito próximo da carga de 34,200 kN necessária para a ruptura estática. Dividindo-se a carga de 28,36 kgf pela área da amostra rompida de 22,70 cm2 (com 11,75 \% de deformação axial), encontra-se a tensão desvio de ruptura de 1,25 kgf/cm2 (ou 122,6 kPa). Esta tensão é próxima à tensão desvio de ruptura estática e durante sua atuação, há significativa queda da tensão confinante efetiva.
A atuação conjunta da tensão desvio de pico e da queda de tensão confinante efetiva explica porque o carregamento provocado pelo choque de 4,100 kgf caindo de $20 \mathrm{~cm}$ é suficiente para levar a amostra à ruptura.

O ensaio de choque no colúvio também mostra acentuado acréscimo de força durante o impacto e rápida estabilização da força de carregamento (figuras 9 e 11). A força pico atinge $0,1428 \mathrm{kN}(14,56 \mathrm{kgf})$, causando aumento de 1,84 vezes em relação à força de $0,0502 \mathrm{kN}$ gerada pelo peso de 5,160 kgf no repouso, após o choque. A carga de pico de 14,56 kgf superou a carga de 10,31 kgf, necessária para ruptura estática. Dividindo a carga de pico pela área de $26,51 \mathrm{~cm} 2$, com deformação axial final de 18,5 \%, foi obtida a tensão desvio de ruptura de $0,55 \mathrm{kgf} / \mathrm{cm} 2$, ou 53,96 kPa. Assim, verificou-se que neste ensaio a tensão desvio foi maior que a tensão desvio estática de $50 \mathrm{kPa}$. A figura 11 traz as variações das tensões confinantes, tensões verticais, tensão desvio e poro-pressão durante o choque. Observa-se um nítido acompanhamento da poro-pressão pela tensão confinante total, porém verifica-se que a diferença entre elas torna-se bem pequena no ápice da curva, que é também o momento de pico de tensão desvio.

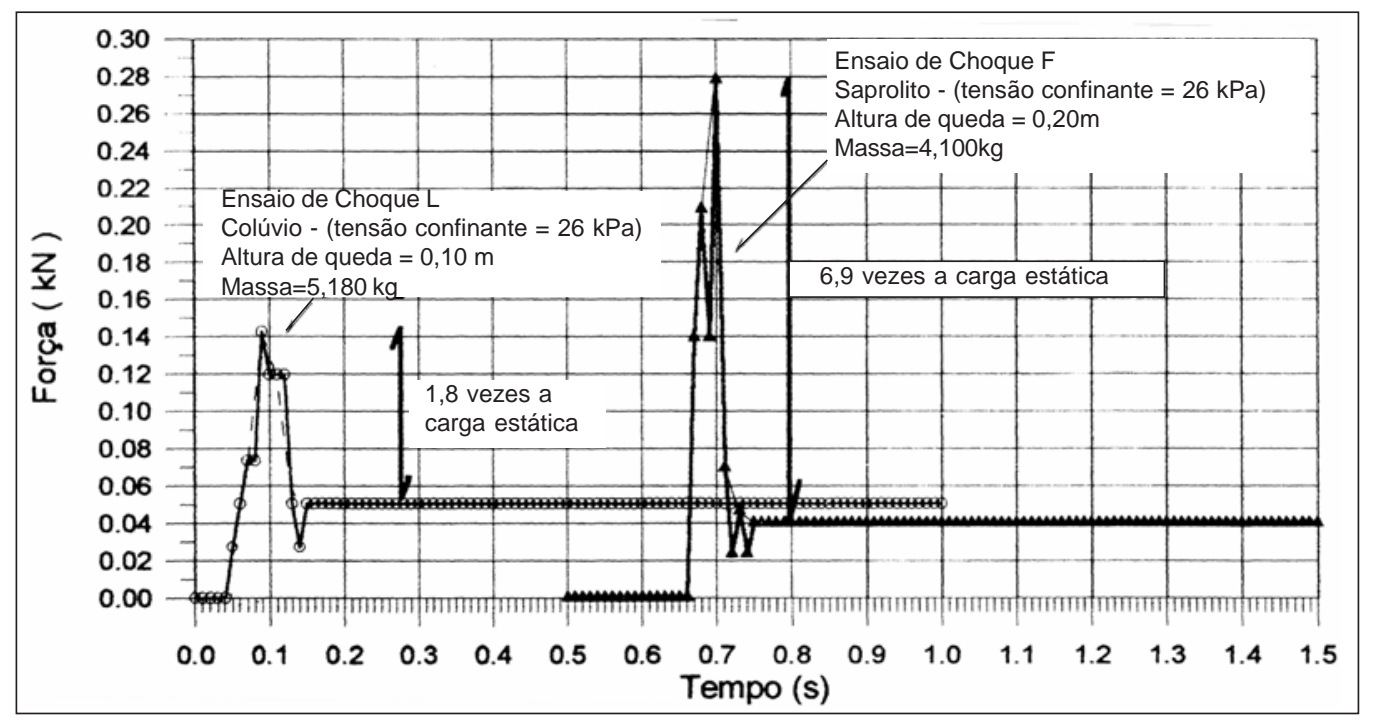

Figura 9 - Força aplicada durante o choque.

Devido a esta atuação conjunta, de novo é visto que a tensão confinante efetiva torna-se menor que a tensão confinante inicial ( $25 \mathrm{kPa}$ ), ao mesmo tempo em que ocorre um aumento de tensão desvio, denotada pelo pico de carregamento. É nesta circunstância que a amostra alcança a ruptura. Este resultado permite dizer que o carregamento de 5,160 kgf, equivalente a $50 \%$ da carga de ruptura estática, é suficiente para geração de ruptura.

A figura 12 traz o gráfico P'Q para os ensaios de choque. Para o saprolito observa-se um caminho de tensões iniciado em $\mathrm{P}^{\prime}=25 \mathrm{kPa}$, que segue em linha reta vertical até atingir a envoltória de ruptura, sobre a qual prossegue até atingir o ponto máximo de tensões. Deste ponto retorna para valores de $\mathrm{Q}$ em torno de $10 \mathrm{kPa}$, com aumento gradativo dos valores de P', até finalizar em P' $=30$ e Q $=10 \mathrm{kPa}$.

No colúvio o comportamento ao choque se assemelha ao caminho de tensões de areias fofas, tal como indica a curva $\mathrm{C}$ da figura 3. Este comportamento é explicado pelo elevado índice de vazios inicial associado à baixa coesão efetiva do colúvio, conferindo ao material um caráter nãocoesivo com estrutura sensível, tal qual as areias fofas. Outra comparação pode ser feita com as curvas $\mathrm{T}_{1}$ e $\mathrm{T}_{3}$ da figura 4 , com trajetórias de tensões semelhantes. 


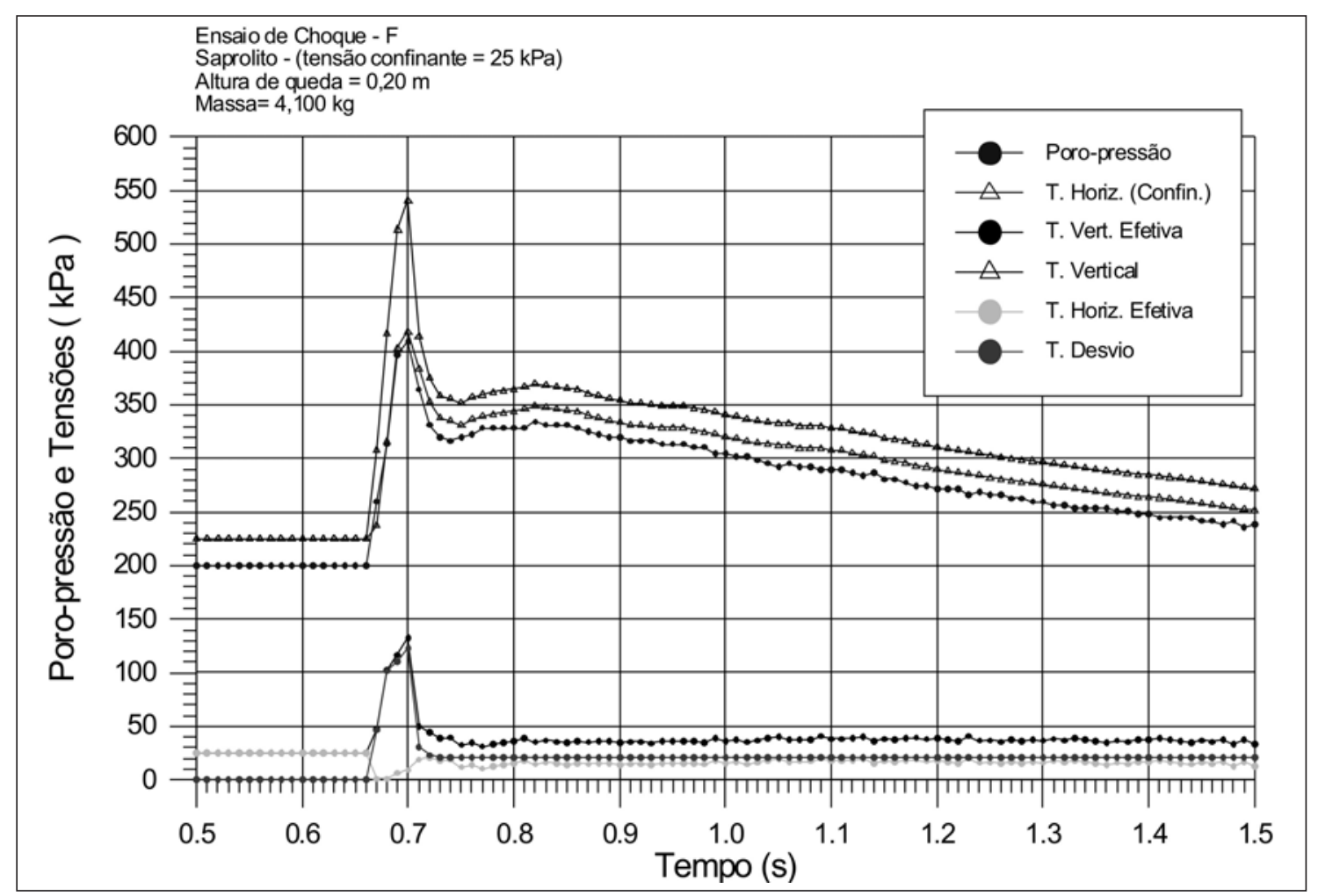

Figura 10 - Variação das tensões e poro-pressões no saprolito, na ruptura provocada pelo choque.

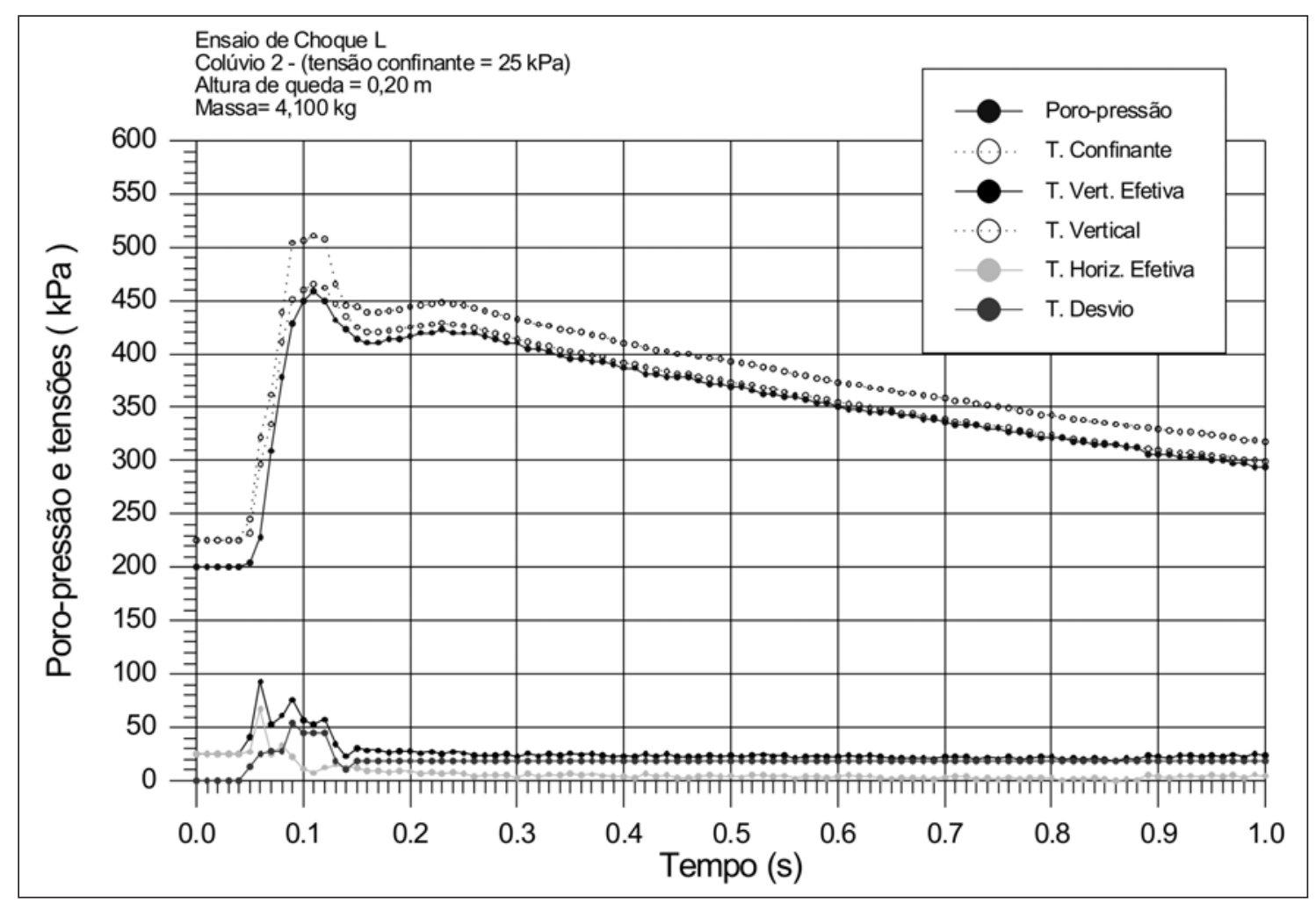

Figura 11 - Variação das tensões e poro-pressões no colúvio na ruptura gerada pelo choque. 


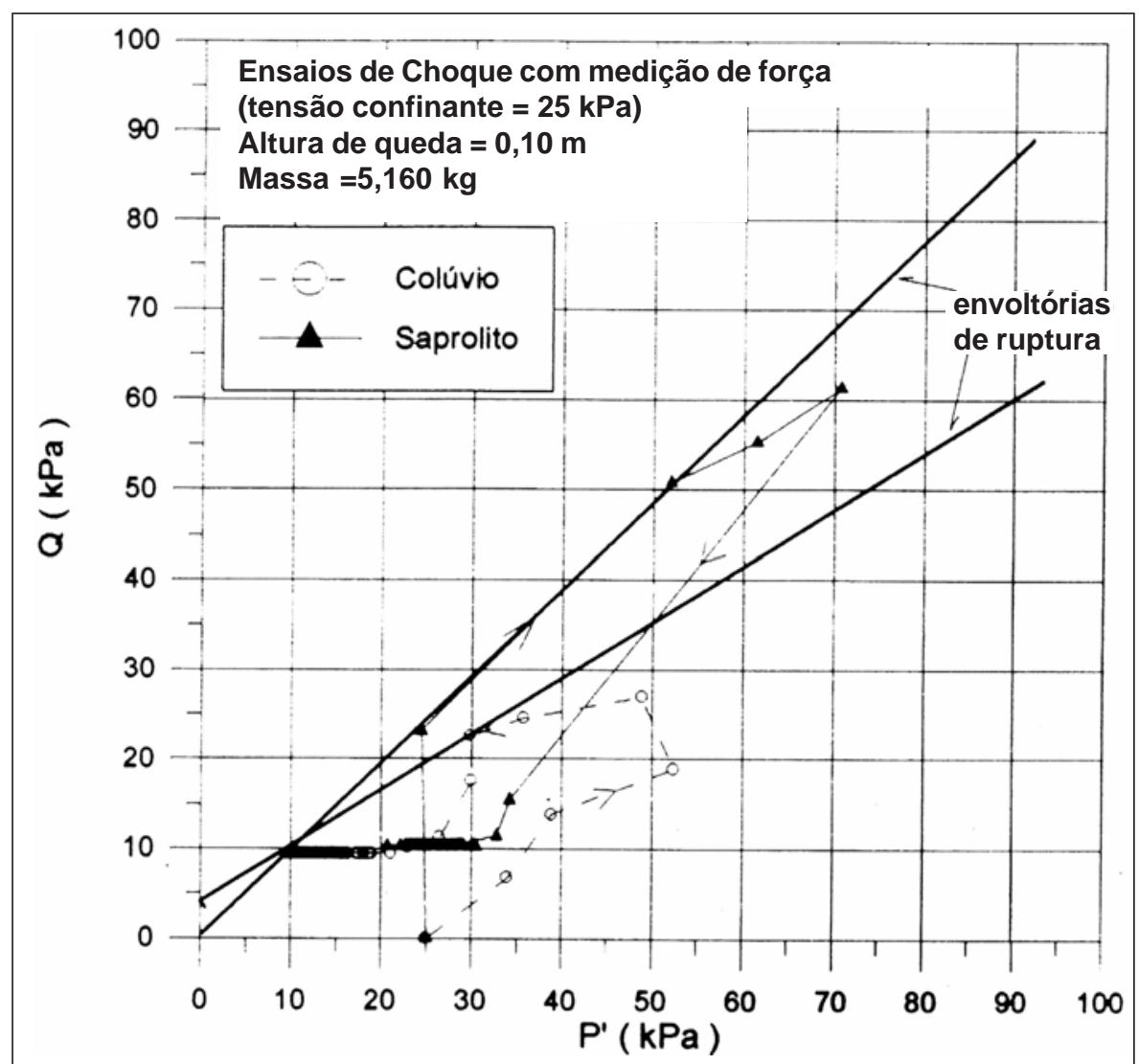

Figura 12 - Gráfico P’- Q dos ensaios de choque no saprolito e no colúvio do Soberbo.

\section{Modelagem da iniciação do fluxo detrítico por choque de bloco rochoso}

Levando-se em conta a literatura e os resultados dos ensaios de choque pode-se admitir a possível iniciação do fluxo detrítico devido à queda de bloco (de diorito). Admitese também que o bloco caiu em queda livre e se chocou no solo sem quicar, onde permaneceu. Admite-se, finalmente, que o bloco de rocha tem forma esférica e diâmetro de $3 \mathrm{~m}$ tal como foi visto na foto de 1954.

O peso específico do diorito situa-se entre 27,47 e 28,45 $\mathrm{kN} / \mathrm{m}^{3}$ (GORSHKOV \& YAKUSHOVA, 1967), logo, o peso específico atribuído ao bloco foi $27,96 \mathrm{kN} / \mathrm{m}^{3}$ (média dos valores), que em toneladas por metro cúbico dá 2,8 ton $/ \mathrm{m}^{3}$. O volume do bloco rochoso é $14,14 \mathrm{~m}^{3}$ e usando o peso específico de $2,8 \mathrm{t} / \mathrm{m}^{3}$, chega-se ao peso do bloco: 39,59 ton.

HANSBO (1978) estudou o carregamento durante o choque, mostrando que o bulbo de deformação assume forma elíptica mais pronunciada do que o bulbo estático. A relação entre a deformação vertical e a influência de profundidade do carregamento estático e dinâmico está na figura 13. Para este autor a profundidade (d) de influência da queda do peso para compactação de terrenos se dá por:

$$
\mathrm{d}=\left(\mathrm{M} \mathrm{H}_{\mathrm{q}}\right)^{0,5}
$$

onde: M é a massa do peso (ton) e $\mathrm{H}_{\mathrm{q}}$ é a altura de queda (m).

\section{Ey \%}

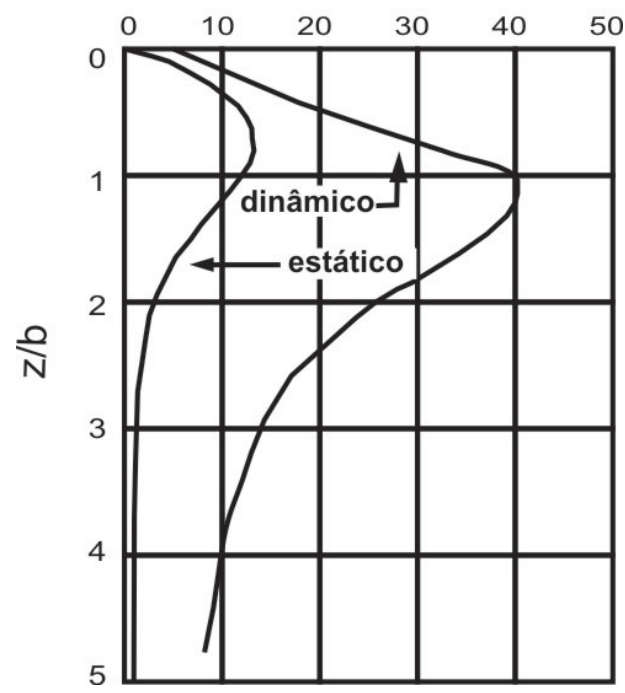

Figura 13 - Variação da deformação vertical $\left(\varepsilon_{\mathrm{v}}\right)$ do solo sob carregamentos dinâmico e estático. A deformação dinâmica é mais pronunciada que a estática na direção vertical (HANSBO, 1978). 
No Soberbo a topografia (figura 6) e a interpretação das aerofotos de 1954 indicam que a posição dos blocos estava na cota de $400 \mathrm{~m}$ e o ponto de impacto, logo a jusante da estrada na zona A do movimento de massa, está em 350 m. Portanto, a altura de queda do bloco é de $50 \mathrm{~m}$. Substituindose este valor e o peso do bloco é de 39,59 t na equação 8, tem-se que a profundidade de influência do choque de 44,5 $\mathrm{m}$, é superior à espessura das camadas de solo na zona A do movimento de massa, onde as sondagens (SCHILLING, 1993) mostraram ter cerca de $10 \mathrm{~m}$.

Adotando a idéia de que no choque o contato blocosolo tem área circular com diâmetro igual a $1 \mathrm{~m} \mathrm{(1/3} \mathrm{do}$ diâmetro), podem ser definidos valores de carregamento e deformações verticais correlatas, através do gráfico da figura 14. Atribuindo ao raio de contato o valor de $0,5 \mathrm{~m}$ (incógnita b do eixo vertical do gráfico) e profundidade $\mathrm{z}=10 \mathrm{~m}$, tem-se a relação $z / b=20$. Correlacionando este resultado com a curva dinâmica da figura 14, vê-se que a deformação vertical deve ser muito baixa na profundidade de $10 \mathrm{~m}$, mas relativamente elevada para profundidades próximas à superfície da encosta. Para a profundidade de $2 \mathrm{~m}$, a relação $\mathrm{z} / \mathrm{b}=4$, colocada no gráfico, resulta numa deformação vertical de $10 \%$.

Considerando que o peso específico do colúvio é de $14,49 \mathrm{kN} / \mathrm{m}^{3}$, nesta profundidade de $2 \mathrm{~m}$ a tensão vertical atuante fica em torno de $29 \mathrm{kPa}$ e é possível considerar que a tensão confinante nesta profundidade situa-se em torno de $25 \mathrm{kPa}$, tal como a tensão confinante nos ensaios de choque realizados. Sabe-se que nos ensaios triaxiais convencionais o colúvio rompe com deformação axial acima de 2 \% (tabela 1) e a queda do bloco produz 10 \% de deformação, logo alcançou a liquefação, conforme mostra a figura 12 .

\section{Conclusão}

Os resultados obtidos e discutidos neste trabalho, permitem afirmar que a queda do bloco gerou a iniciação do fluxo detrítico do Soberbo em 14/JAN/1966. Esta condição pode ser alcançada em outras localidades do Maciço da Tijuca, assim como em outros domínios montanhosos sob condições lito-estruturais similares. Com efeito, muitos dos casos de deslizamentos ocorridos na porção ocidental do Maciço da Tijuca, em resposta às chuvas intensas de Fevereiro de 1996, concentraram-se próximo da zona de cumeada onde inúmeros blocos in situ de granitos estão suscetíveis ao deslocamento e queda.

Certamente que o mecanismo ora focalizado não exclui a possibilidade de que no evento extremo de chuvas de 1996 outros mecanismos possam ter deflagrado os inúmeros casos de deslizamentos do tipo fluxo detrítico ocorridos no Maciço da Tijuca, assim como no Maciço da Pedra Branca.

Finalmente, vale comentar que nos domínios montanhosos, em geral, a ocorrência de espessos colúvios ricos em blocos atestam a mobilidade dos blocos em tempo geológico passado, assim como ocorre nos dias atuais.

\section{Agradecimentos}

Ao CNPq (PRONEX, Universal e CT-Hidro), FAPERJ (PADCT e Cientista do Estado).

\section{Referências Bibliográficas}

Amaral, C.P.; Barros, W.T., \& Porto Jr., R. (1992) "The structural control within a landslide in Rio de Janeiro", 6th Intern. Symp. on Landslides, New Zealand, v.3, pp. 1339-1343.

Avelar, A.S. (1996) Investigação histórica e geotécnica do movimento de massa do Soberbo (RJ). T. M.Sc., COPPE/UFRJ, Rio de Janeiro, 122p.

Avelar, A.S. \& Lacerda.W.A (1997) Causas iniciais do movimento de massa do Soberbo, RJ - Brasil, II Simp. Panam. sobre Escorregamentos e II Conf. Bras. Estab. de Encostas - COBRAE, Rio de Janeiro, v.1, pp. 3-12.

Barata, F. (1969) “Landslides in the Tropical Region of Rio de Janeiro”, Proc. 7th Int. Conf. Soil Mech. and Found. Eng,, México, v.2, p 507-516.

Barros,W.T.; Bogossian, F. \& Lopes, P.C.C., (1992) “O escorregamento do Soberbo”, Publ. Esp. I Conf. Bras. Estab. de Encostas COBRAE, Rio de Janeiro, $14 \mathrm{p}$.

Bovis, M.J. \& Dagg, B.R. (1992) “Debris flow triggering by impulsive loading: mechanical modeling and case studies”, Canadian Geotech. J., v.29, pp.345-352.

Coelho Netto, A.L. (1985) Surface hydrology and soil erosion in a Tropical mountainous rainforest drainage basin, Rio de Janeiro. PhD Thesis - Katholieke Univ. Leuven, Belgium, 181p.

Cruz, E.S.; Vilela, C.L.; Azeredo, M. \& Coelho Netto, A.L.1998- Influência da geomorfologia e da vegetação na geração de cicatrizes de erosão: maciço da Tijuca/RJ. II Simp Nac. Geomorf., Santa Catarina:359-364.

Eckersley, D., 1990, “Instrumented laboratory flowslides”, Géotechnique, v. 40, n. 3, pp. 489-502.

Evans, S.G. \& Hungr, O., 1993, "The assessment of rockfall hazard at the base of talus solpe", Canadian Geothec. J., v. 30, pp. 620-636.

Fonseca, A.M.M.C.C., (1969), "Relato sobre causas e problemas das encostas da Guanabara”, 1a Semana Paulista de Geologia Ap., São Paulo, v.1, p.1-10. 
Gorshkov, G. \& Yakushova, A., (1967) "Physical Geology”, Mir Pub., Moscow, 596 p.

Hansbo, S., (1978) "Dynamic consolidation of soil by a falling weigth”, Ground Engineering, v.II, n.5, p. 27-36.

Hiura, H.; Sassa, K.; Kitera, N. \& OHTE, K., 1985, “Case study of the Nakaba liquefied landslide", IVth Intern. Conf. and Field Workshop on Landslides, Tokyo, Japan, pp. 299-304.

Hungr, O. (1995) “A model for runout analysis of rapid flow slides, debris flows and avalanches”, Canadian Geotech. J., v.32, pp. 610-623.

Hungr, O. (2002) “Analytical models for slides and flows” Proc. Int.. Symp. on Landslide Risk, Mitigation and Protection of Cultural and Natural Heritage, Kyoto, Japan, pp. 559-586.

Innes, J.L. (1983) “Debris flows”, Progress in Physical Geog., v.7, pp. 353-358.

Iverson, R.M.; Delinger, R.P.; Lahusen, R.G. \& Logan, M. (2000) "Two phase debris flows across 3-D terrain: model predictions and experimental tests”, pp. 521529, in:WICKZOREK, G.F. \& NAESER, N.D. (eds.), Debris-flow hazards mitigation: mechanics, prediction and assessment. Teipei, Taiwan, Ed. Balkema, 608 p.

Johnson, A.M. \& Rodine, J.R., 1984, "Debris flow"', in: BRUNSDEN, D. \& PRIOR, D.B. (ed), Slope Instability, ch. 8, London, John Willey e Sons, 620p.

Kubota, T. \& Takeda, Y. (1998) "Initiation of rapid and slow landslides in experimental model”, Proc. Envirom. Forest Science, Kyoto, Japan, s/ pp.

Meis, M.R.M \& Silva, J.X. (1968), “Considerações geomorfológicas a propósito dos movimentos de massa ocorridos no Rio de Janeiro”, Rev. Bras. Geografia, ano 30, n. 1, p 55-73.

Pedrosa, M.G.A.; Soares, M.M. \& LACERDA,W.A., (1988), "Mechanism of movements in colluvial slopes in Rio de Janeiro”, Proc. 5th Int. Symp. Landslides, Lausane, v.2, p. 1211-1216.

Pellerin, J., Gama, A.M.C., Nascimento, E.E. J., Valdati, J. Paisani, J.C. \& Pontelli, M.E. (1996) Zoneamento e efeitos morfodinâmicos da enxurrada do dia 23.12.95 nas bacias dos rios Figueira e Pinheirinho, SC, Rev. Soc. e Natureza, Uberlândia, n. 15, p. 195200.

Pierson, T.C. \& Costa, J.E. (1987) “A rheologic classification of subaerial sediment-water flows", Reviews in Eng. Geology, VII, Debris flows/Avalanches: Process, Recognition and Mitigation., Geol. Soc. Am., pp. 1-12.
Reneau, S.L. \& Dietrich, W.E. (1987) The importance of hollows in debris flow studies: Examples from Marin County, California, Reviews in Eng. Geology, VII, Debris flows/Avalanches: Process, Recognition and Mitigation., Geol. Soc. Am., pp. 165-180.

Santos Jr., O.F., (1996) "Estudo experimental do comportamento de um solo residual submetido a variações cíclicas de poro-pressão", T. DSc, COPPE/UFRJ, Rio de Janeiro, 284 p.

Sassa, K. (1985) “The mechanism of debris flow”, 11th Int. Conf. Soil Mech. and Found. Eng, San Francisco, v.3, pp. 1173-1176.

Sassa, K. (1989) “Geotechnical classification of landslides”, Landslide News, n.3, pp.21-24.

Schilling, G.H. (1993) "Instrumentação e análise dos movimentos da encosta do Soberbo, Alto Boa Vista, RJ”, T. MSc, COPPE/UFRJ, Rio de Janeiro, $237 \mathrm{p}$.

Silveira, G.C. (1993) “Características geomecânicas dos solos residuais e coluvionares do escorregamento na estrada do Soberbo, Alto da Boa Vista, Rio de Janeiro”, T. MSc, COPPE/UFRJ, Rio de Janeiro, $295 \mathrm{p}$.

Silveira, G.C., \& Lacerda, W.A. (1992) Caracterização mineralógica dos solos residuais e coluvionares do escorregamento do Soberbo, I Conf. Bras. Estab. Encostas COBRAE, Rio de Janeiro, v. 1, p. 479-490.

Takahashi, T., 2000, "Initiation and flow of various types of debris-flow”, pp. 15-28, in: Wickzorek, G.F. \& Naeser, N.D. (eds.), Debris-flow hazards mitigation: mechanics, prediction and assessment. Teipei, Taiwan, Ed. Balkema, 608 p.

Vieira, B.C; Vieira, A.C.F; Fernandes, N.F. \& Amaral, C.P. (1997) "Estudo comparativo dos movimentos de massa ocorridos em fevereiro de 1996 nas bacias do Quitite e do Papagaio (RJ): uma abordagem geomorfologica”, II Simp. Panam. Escorregamentos e II Conf. Bras. Estab. de Encostas - COBRAE, Rio de Janeiro, v.1, pp. 165174. 